\title{
FORMULATION AND EVALUATION OF FLOATING IN SITU GEL OF CIPROFLOXACIN
}

\author{
SHAILAJA PASHIKANTI ${ }^{*}$, JYOTHSNA B. ${ }^{2}$ \\ ${ }^{1} \mathrm{AU}$ College of Pharmaceutical Sciences, Andhra University, Visakhapatnam, 530003. Andhra Pradesh, India, ${ }^{2}$ Pullareddy Institute of \\ Pharmacy, Hyderabad, Telangana, India \\ Email: dr.pshailaja@andhrauniversity.edu.in \\ Received: 18 Jul 2018, Revised and Accepted: 12 Dec 2018
}

\begin{abstract}
Objective: The objective of the study was to develop floating in situ gel formulations of Ciprofloxacin that has a narrow absorption window and mainly absorbed in the proximal areas of GIT. These formulations increases the targeted action on bacteria for a longer time that can be used in the treatment of Helicobacter pylori (H. pylori) infections and urinary tract infections.

Methods: In situ gel formulations were prepared by varying concentrations of sodium alginate as in situ gel forming bio-degradable polymer and calcium carbonate as a cross-linking agent. The formulations were evaluated for Physical appearance, $\mathrm{pH}$, in vitro drug release, viscosity, in vitro floating behaviour, in vitro gelling capacity and drug content. FTIR was conducted for Ciprofloxacin, excipients used and optimized formulation.

Results: All the formulations showed an optimum viscosity that will allow ease of administration and swallowing. Floating lag time of all formulations was between $32-70$ seconds and floated for $>12 \mathrm{~h}$. The in vitro gelling capacity increased with increasing the polymer and gelling agent concentrations. Increase in polymer concentration decreased the rate and extent of the drug release. Among all the formulations, $\mathrm{F} 4 \mathrm{containing} 4 \% \mathrm{w} / \mathrm{v}$ of sodium alginate and $4 \% \mathrm{w} / \mathrm{v}$ of calcium carbonate showed sustained in vitro drug release (95.6\%) over an extended period of $12 \mathrm{~h}$. FTIR studies revealed no interaction between drug and excipients used. Drug release from the formulations followed First order kinetics with Fickian diffusion.
\end{abstract}

Conclusion: Ciprofloxacin was successfully formulated as a pH-triggered floating in situ gelling system using sodium alginate.

Keywords: In situ gel, Sodium alginate, Calcium carbonate, Ciprofloxacin

(C) 2019 The Authors. Published by Innovare Academic Sciences Pvt Ltd. This is an open access article under the CC BY license (http://creativecommons.org/licenses/by/4.0/) DOI: http://dx.doi.org/10.22159/ijap.2019v11i1.28603

\section{INTRODUCTION}

Oral administration is the most convenient and preferred means of drug delivery to the systemic circulation. Oral controlled release drug delivery has recently been of increasing interest to achieve improved therapeutic advantages, such as ease of administration, patient compliance, and flexibility in formulation. In situ gel-forming polymeric formulations is in sol form before administration undergo gelation in situ to form a gel [1]. These in situ solutions are liquid at room temperature but undergo gelation when in contact with body fluids or change in $\mathrm{pH}$. These have a characteristic property of temperature dependent, $\mathrm{pH}$-dependent and cation induced gelation. Compared to conventional controlled release formulations, in situ forming drug delivery systems possess potential advantages like simple manufacturing process, ease of administration, reduced frequency of administration, and improved patient compliance and comfort [2-4]. Floating in situ gel drug delivery systems have been used to deliver many drugs which are used either for their systemic or for their local effects in the stomach [5]. A major constraint in the oral controlled drug delivery is that not all drug candidates are absorbed uniformly throughout the gastrointestinal tract (GIT), and some drugs are absorbed only in a particular portion of GIT or absorbed to a different extent in various segments of the GIT. The pH-dependent solubility and stability levels of a drug play an important role in its absorption. In the case of the drug Ciprofloxacin $\mathrm{HCl}(\mathrm{CPF} \mathrm{HCl})$, it has a narrow absorption window and mainly absorbed in the proximal areas of GIT [6]. Therefore, the researchers were developed certain gastro retentive systems of $\mathrm{CPF} \mathrm{HCl}$ such as floating systems $[7,8]$. Ciprofloxacin belongs to the family of quinolones (the term refers to potent chemotherapeutic antibacterial agents) [9]. Ciprofloxacin is a broad-spectrum antibiotic active against both Gram-positive and Gram-negative bacteria. It functions by inhibiting DNA gyrase, a Type II topoisomerase and topoisomerase IV, enzymes necessary to separate bacterial DNA, thereby inhibiting cell division and also affect mammalian cell replication [10]. The objective of the present study was to develop ciprofloxacin floating in situ gel that remains in the stomach, resulting in increased gastric residence time and thus increases the local concentration of the drug for complete eradication of $H$. pylori [5]. The present investigation deals with the formulation, optimization, and evaluation of Sodium alginate, HPMC $\mathrm{K} 100 \mathrm{M}$ based floating oral in situ gel of $\mathrm{CPF} \mathrm{HCl}$ in which calcium carbonate, sodium alginate were used as a cross-linking agent. The gel was evaluated for parameters like floating lag time, floating duration, gel strength, density, viscosity, $\mathrm{pH}$, in vitro drug release, drug content, and in vitro gelling capacity.

\section{MATERIALS AND METHODS}

\section{Materials}

Ciprofloxacin $\mathrm{HCl}$ (Gift sample procured from Dr. Reddy's Laboratories, India), sodium alginate and Hydroxyl propyl methyl cellulose (HPMC K100M) (Yarrow Chem, India), sodium citrate, methylparaben and propylparaben (Himedia Laboratories, India). All other reagents were of analytical grade.

\section{Methods}

Preparation of floating in situ gels of ciprofloxacin

Sodium alginate form pH-triggered in situ gel in the presence of calcium ions as a cross-linking agent in the gastric fluid. Sodium alginate solutions of different concentrations were prepared by dissolving the specified amount of sodium alginate in $100 \mathrm{ml}$ of distilled water. The appropriate amount of sodium alginate, $0.4 \% \mathrm{w} / \mathrm{v}$ of HPMCK100M and $0.5 \% \mathrm{w} / \mathrm{v}$ of sodium citrate were dissolved in sufficient amount of distilled water and stirred for $20 \mathrm{~min}$ on the mechanical stirrer (M/s. Remi, Model: RQ-124 A/D) for complete swelling of polymers. Drug solution containing $500 \mathrm{mg}$ of the drug in $17 \mathrm{ml}$ of $0.1 \mathrm{~N} \mathrm{HCl}$ was slowly added to $20 \mathrm{ml}$ of polymer solution with continuous stirring on the mechanical stirrer for $15 \mathrm{~min}$. Specified concentrations of $\mathrm{CaCO}_{3}$ were prepared in distilled water and add to the polymer solution while stirring, continue stirring for $10 \mathrm{~min}$. For the final preparation directly add $0.09 \% \mathrm{w} / \mathrm{v}$ of methylparaben, $0.09 \%$ $\mathrm{w} / \mathrm{v}$ of propylparaben and continue stirring for $2 \mathrm{~min}$. Finally, make up the volume to $50 \mathrm{ml}$ with distilled water. A composition of different formulations of ciprofloxacin were shown in table 1. 
Table 1: In situgel compositions of different formulations of ciprofloxacin

\begin{tabular}{|c|c|c|c|c|c|c|c|c|}
\hline Ingredients (mg) & F1 & F2 & F3 & F4 & F5 & F6 & F7 & F8 \\
\hline Ciprofloxacin & 500 & 500 & 500 & 500 & 500 & 500 & 500 & 500 \\
\hline HPMC K100M & 200 & 200 & 200 & 200 & 200 & 200 & 200 & 200 \\
\hline Sodium alginate & 500 & 1000 & 1500 & 2000 & 500 & 1000 & 1500 & 2000 \\
\hline Calcium carbonate & 500 & 1000 & 1500 & 2000 & 250 & 500 & 750 & 1000 \\
\hline Sodium citrate & 250 & 250 & 250 & 250 & 250 & 250 & 250 & 250 \\
\hline Methylparaben & 45 & 45 & 45 & 45 & 45 & 45 & 45 & 45 \\
\hline Propylparaben & 45 & 45 & 45 & 45 & 45 & 45 & 45 & 45 \\
\hline Distilled water up to (ml) & 50 & 50 & 50 & 50 & 50 & 50 & 50 & 50 \\
\hline
\end{tabular}

\section{Evaluation}

\section{Fourier Transform Infrared (FTIR) compatibility studies}

Compatibility studies of drug and the polymer were carried out by using fourier transform infrared spectroscopy (FTIR). Fourier transform infrared spectra of the samples were obtained in the range of 4000 to $450 \mathrm{~cm}^{-1}$ using an FTIR (M/s Shimadzu, Model: IR Spirit) by the $\mathrm{KBr}$ disc method [11].

\section{Determination of drug content}

Accurately, $10 \mathrm{ml}$ of the formulation (containing the equivalent of 30 mg (PF $\mathrm{HCl}$ ) from completely different batches was measured and transferred to a $100 \mathrm{ml}$ volumetric flask. To the current $50-70 \mathrm{ml}$ of $0.1 \mathrm{~N}, \mathrm{HCl}$ was sonicated for $30 \mathrm{~min}$. Volume was adjusted to a 100 ml. Complete dispersion of the contents was ensured visually, and therefore the dispersion was filtered through Whatman's paper. From this answer, $10 \mathrm{ml}$ of the sample was withdrawn and diluted to a $100 \mathrm{ml}$ with $0.1 \mathrm{~N} \mathrm{HCl}$. The contents of the compound were measured at most absorbance at $237 \mathrm{~nm}$ using double beam UV Visible Spectrophotometer (M/s. Elico, Model: SL210) [12].

\section{pH measurement}

The $\mathrm{pH}$ of the prepared formulations was measured using a calibrated digital pH meter (M/s. Elico, Model: LI120) [13].

\section{The viscosity of in-situ gelling solutions}

A viscosity of the all the prepared in situ gel formulations are studied by using Brookfield Viscometer.

\section{In vitro gelation study}

To evaluate in vitro gelling capability, accurately measured $10 \mathrm{ml}$ of formulation was added to a $100 \mathrm{ml}$ of $0.1 \mathrm{~N} \mathrm{HCl}$ at $37^{\circ} \mathrm{C}$ in a beaker with gentle agitation that avoids breaking of farmed gel. The in vitro gelling capability was categorized into 3 classes on the idea of the stiffness of farmed gel, gelation time and period that the gel remains intrinsically [14].

(+) Gels after few minutes dispersed rapidly

$(++)$ Gelation immediate remains for few hours
$(+++)$ Gelation immediate remains for an extended period

\section{In vitro floating study}

The in vitro floating study was administered by introducing $10 \mathrm{ml}$ of the formulation into a beaker containing $900 \mathrm{ml}$ of $0.1 \mathrm{~N} \mathrm{HCl}(\mathrm{pH} 1.2)$ at $37^{\circ} \mathrm{C}$ without much disturbance. The time the formulation took to emerge on the medium surface (floating lag time) and also the time the formulation perpetually floated on the surface of the dissolution medium (Duration of floating) were recorded $[15,16]$.

\section{In vitro drug release study}

The dissolution studies were performed using type USP II (paddle method) dissolution apparatus (M/s. Labindia, Model: DS 8000). The dissolution medium used was $900 \mathrm{ml}$ of $0.1 \mathrm{~N} \mathrm{HCl}$ maintained at $37^{\circ}$ C. The stirring rate was adjusted to $50 \mathrm{rpm}$. This speed was believed to stimulate the in vivo existing delicate agitation and was slow enough to avoid the breaking of the gelled formulation. At the predetermined time intervals, $1 \mathrm{ml}$ samples were withdrawn and replaced by fresh dissolution medium, filtered through Whatman's paper, diluted and assayed at $237 \mathrm{~nm}$ using double beam UV Visible Spectrophotometer $[17,18]$.

\section{RESULTS AND DISCUSSION}

\section{FTIR interpretation studies}

Spectra's of drug and drug, polymer mixtures were given in fig. 1,2,3 and 4. No interaction was observed between drug and polymer. In FTIR spectra of ciprofloxacin, one prominent characteristic peak was found between 3500 and $3450 \mathrm{~cm}^{-1}$, which was assigned to stretching vibration of $\mathrm{OH}$ groups and intermolecular hydrogen bonding. Another band at 3000-2950 $\mathrm{cm}^{-1}$ represented alkene and aromatic C-H stretching, mainly C-H. 1950 to $1450 \mathrm{~cm}^{-1}$ region exhibited FTIR absorption from a wide variety of double-bonded functional groups. The band at 1750 to $1700 \mathrm{~cm}^{-1}$ represented the carbonyl $\mathrm{C}=0$ stretching, i.e., $\mathrm{C}=0$. The peak between 1650 and $1600 \mathrm{~cm}^{-1}$ was assigned to quinolones. The band from 1450 to $1400 \mathrm{~cm}^{-1}$ represented $\mathrm{C}=0$ and at 1300 to 1250 $\mathrm{cm}^{-1}$ suggested bending vibration of the $\mathrm{O}-\mathrm{H}$ group which proved the presence of carboxylic acid. A strong absorption peak between 1050 and $1000 \mathrm{~cm}^{-1}$ was assigned to a C-F group. From FTIR studies, it is clear that there is no interaction between drug and polymers.

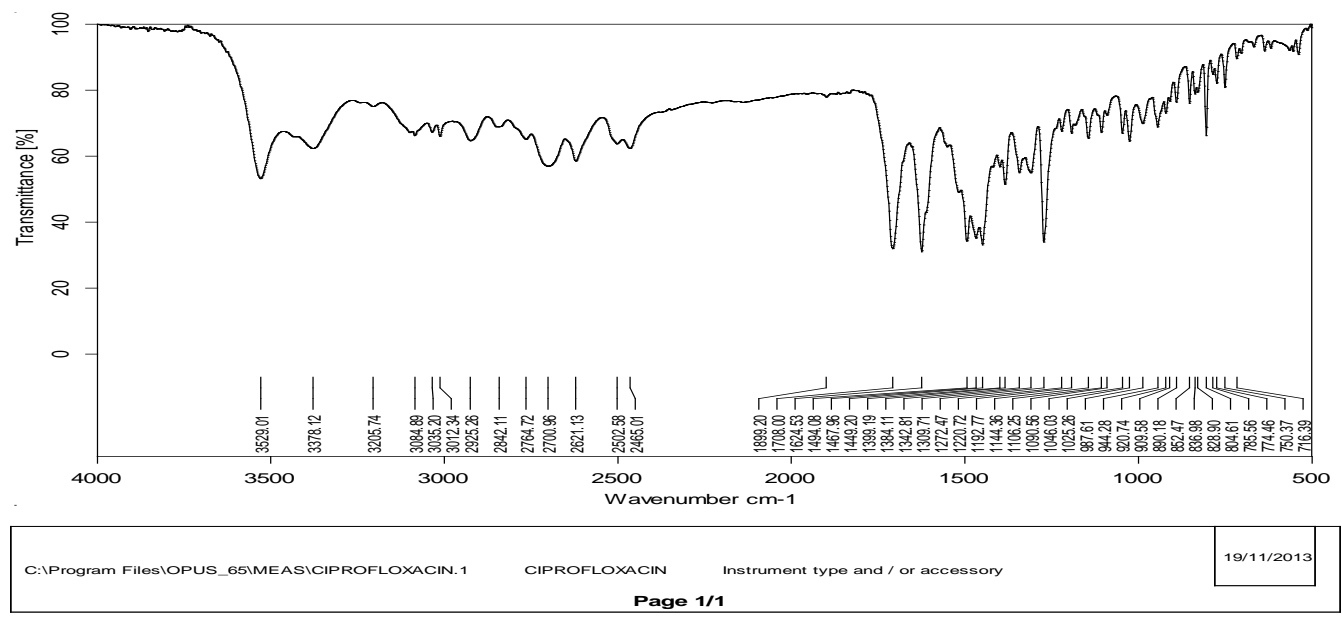

Fig. 1: FTIR spectra of ciprofloxacin 


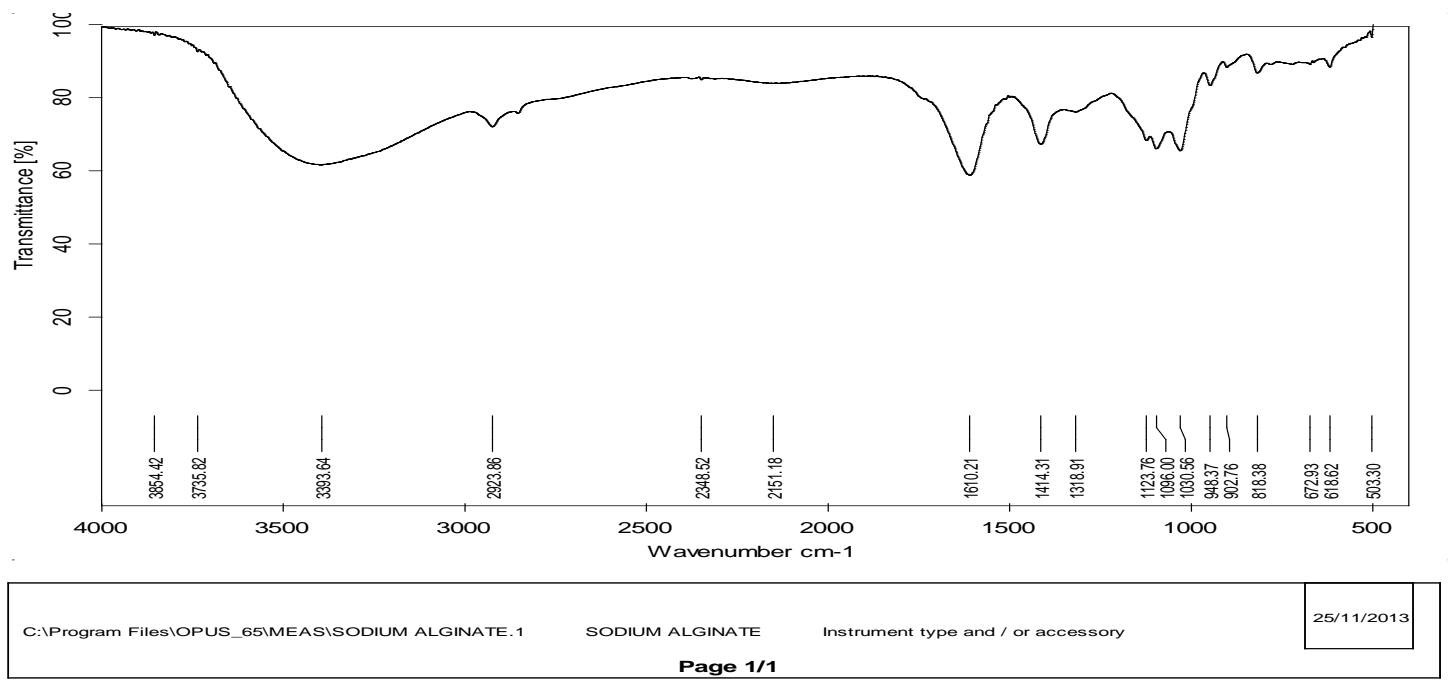

Fig. 2: FTIR spectra of sodium alginate

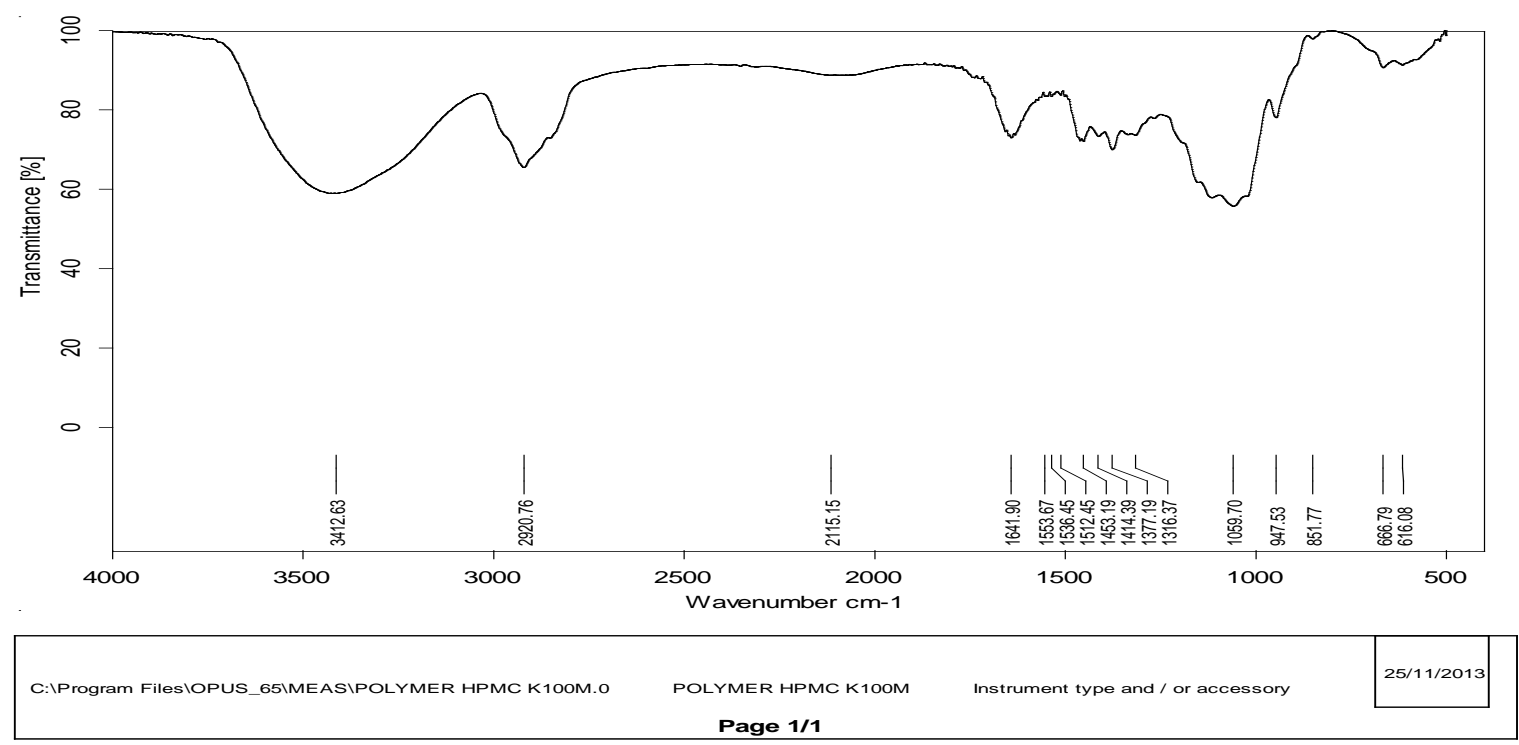

Fig. 3: FTIR spectra of HPMC K100M

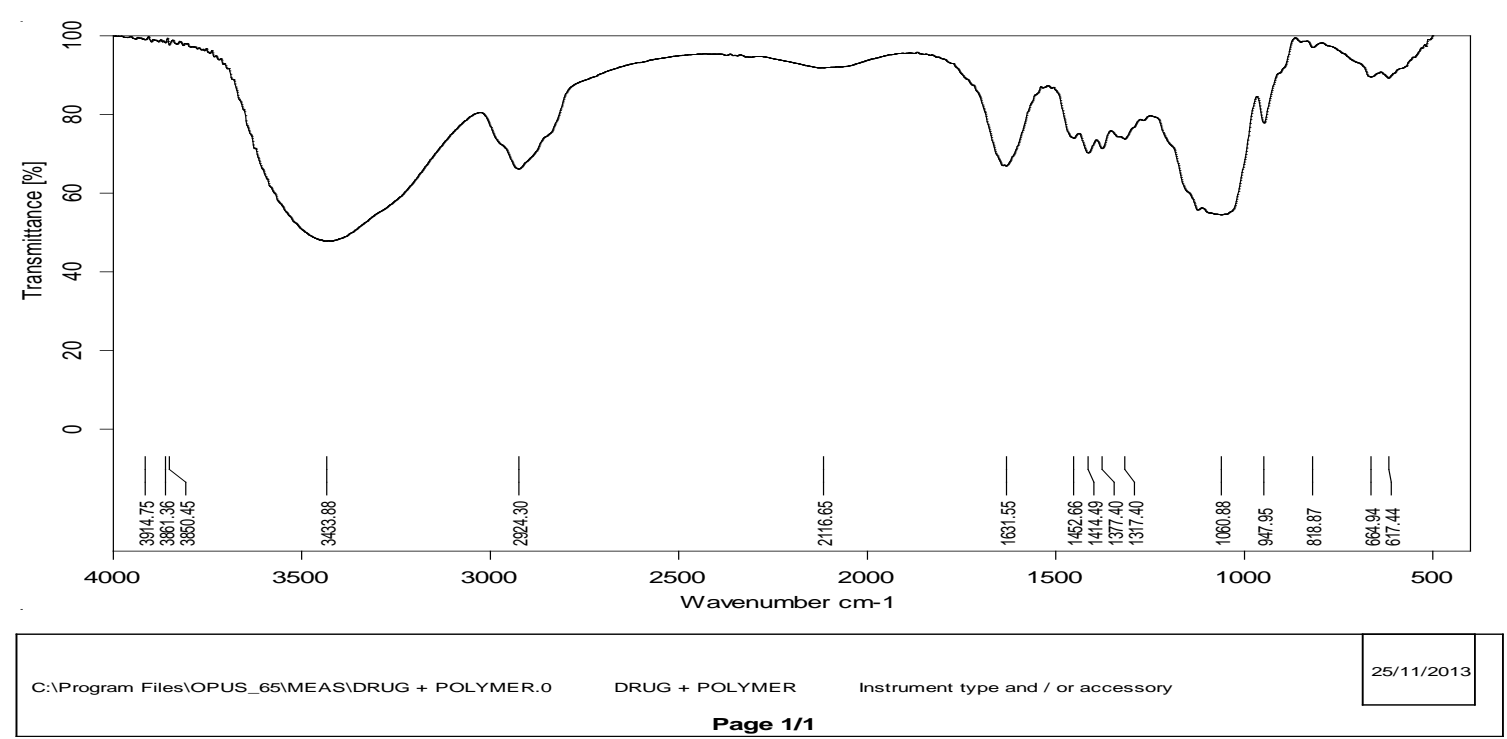

Fig. 4: FTIR spectra of the formulation 


\section{Physical appearance and $\mathrm{pH}$}

The measurement of $\mathrm{pH}$ is very important for oral preparations, otherwise, it leads to irritation to the throat. All the formulations had a slightly acidic $\mathrm{pH}$. The $\mathrm{pH}$ of formulations was found in the range of 5.80-5.93 as shown in table 2 .

\section{The viscosity of in situ gelling solutions}

The formulation should have an optimum viscosity that will allow ease of administration and swallowing as a liquid and produce satisfactory gel strength for use as a delivery vehicle. Results of viscosity for formulations F1 to F8 are shown in table 2 . The formulations showed an increase in viscosity with increasing the concentration of gel forming polymer sodium alginate as a consequence of the increase in chain interaction. The concentration of sodium alginate $(2000 \mathrm{mg}$ and $1500 \mathrm{mg}$ ) was found to produce a satisfactory viscosity increase which provides sustained release of the drug. Calcium carbonate also contributes to increasing the viscosity of the formulations. The viscosity of formulation increased with an increase in sodium alginate and calcium carbonate concentration. As calcium carbonate increases cross-linking tendency of sodium alginate, increase in calcium carbonate concentration also increases viscosity. The viscosity of formulations was in between 140-390 centipoise.

\section{In vitro floating behaviour}

The time is taken by the formulation to emerge on the surface of the medium (floating lag time) and the time for which the formulation constantly floated on the dissolution medium surface (duration of floating) is shown in (table 2). In contact with the gastric environment, calcium carbonate effervesced, releasing carbon dioxide and calcium ions. Then, gelation and complexation by $\mathrm{Ca}^{+2}$ ions took place to provide a gel barrier at the surface of the formulation. The released carbon dioxide was entrapped in the gel network producing a buoyant preparation, which resulted in extended floating. The floating properties of the formulation, mainly depend on calcium carbonate, on increasing the calcium carbonate concentration, the floating lag time was reduced, and the duration of floating was extended [21]. The increasing amounts of $\mathrm{Ca}^{+2}$ and $\mathrm{CO}_{2}$ Gel strength resulted from the increase in calcium carbonate concentration, are responsible for the observed reduction in floating lag time and increasing duration of floating.

Floating lag time and floating time were shown in table 2. The floating lag time is minimum for F1 and highest to F8. This is because F4 and F8 contain the highest concentration of calcium carbonate. Increase in polymer concentration results in an increase in viscosity. Hence time taken from the sol to form a cohesive gel mass and to emerge on the surface of the medium was lowered. The in vitro floating test revealed the ability of all formulations to maintain buoyancy for more than $12 \mathrm{~h}$. All formulations exhibited total floating time of $>12 \mathrm{~h}$. Floating lag time varied with formulation variables. Floating lag time of all formulations were in between 32$70 \mathrm{~s}$.

\section{In vitro gelling capacity}

Gelling studies were carried out using $0.1 \mathrm{~N} \mathrm{HCl} \mathrm{(pH} \mathrm{1.2),} \mathrm{and} \mathrm{the}$ obtained data were represented in table 2. Gelation occurs when the insoluble calcium carbonate solubilize when it comes in contact with acidic medium releasing carbon dioxide and calcium ions. The calcium ions interact with the anionic polymer (sodium alginate) in the formulation causing instantaneous gelation and provide a gel barrier that restricts drug release [20]. As the concentration of the polymer and calcium carbonate increases the in vitro gelling capacity also increases. F1 and F5 formulations had somewhat less stiff gels when compared to other formulations.

\section{Drug content}

The percentage of drug content for all formulations was determined and shown in table 2 . The drug content was found to be in the range of $96.5-98.5 \%$ for all the formulations indicating a uniform distribution of the drug.

Table 2: Evaluation parameters of in situ gel formulations of ciprofloxacin

\begin{tabular}{|c|c|c|c|c|c|c|}
\hline Batch & pH & Viscosity (centipoise) & Floating lag time(s) & Total floating time(h) & Gelling capacity & Drug content (\%) \\
\hline F1 & 5.83 & 180 & $35 \pm 2$ & $>12$ & ++ & $98.2 \pm 1.1$ \\
\hline $\mathrm{F} 2$ & 5.93 & 250 & $38 \pm 1$ & $>12$ & +++ & $97.4 \pm 1.3$ \\
\hline F3 & 5.80 & 310 & $45 \pm 2$ & $>12$ & +++ & $96.5 \pm 1.2$ \\
\hline F4 & 5.86 & 390 & $61 \pm 2$ & $>12$ & +++ & $97.5 \pm 1.3$ \\
\hline F5 & 5.83 & 140 & $37 \pm 3$ & $>12$ & ++ & $98.5 \pm 1.1$ \\
\hline F6 & 5.80 & 210 & $43 \pm 2$ & $>12$ & +++ & $97.9 \pm 1.0$ \\
\hline F7 & 5.83 & 270 & $52 \pm 3$ & $>12$ & +++ & $96.8 \pm 1.5$ \\
\hline F8 & 5.82 & 315 & $70 \pm 2$ & $>12$ & +++ & $97.7 \pm 1.6$ \\
\hline
\end{tabular}

$(\mathrm{n}=3$, mean $\pm \mathrm{SD})$

Table 3: Dissolution data of ciprofloxacin in situ gel formulations

\begin{tabular}{|c|c|c|c|c|c|c|c|c|c|}
\hline \multirow[t]{2}{*}{ Time (h) } & \multicolumn{9}{|c|}{$\%$ Cumulative drug released $(n=3$, mean $\pm S D)$} \\
\hline & F1 & F2 & F3 & F4 & F5 & F6 & F7 & F8 & $\mathbf{M}$ \\
\hline 0.5 & $55.6 \pm 1.2$ & $50.4 \pm 1.3$ & $43.7 \pm 1.7$ & $38.5 \pm 1.9$ & $60.2 \pm 1.6$ & $54.6 \pm 1.9$ & $46.8 \pm 1.4$ & $41.2 \pm 1.5$ & $38.5 \pm 1.3$ \\
\hline 1 & $60.8 \pm 1.7$ & $54.2 \pm 1.5$ & $49.2 \pm 1.2$ & $42.7 \pm 1.6$ & $67.3 \pm 1.4$ & $57.6 \pm 1.4$ & $50.6 \pm 1.2$ & $45.5 \pm 1.2$ & $64.2 \pm 1.4$ \\
\hline 2 & $69.6 \pm 1.5$ & $59.6 \pm 2.0$ & $54.9 \pm 1.5$ & $49.5 \pm 1.7$ & $74.6 \pm 1.3$ & $65.7 \pm 1.3$ & $58.7 \pm 1.5$ & $51.2 \pm 1.5$ & $82.5 \pm 1.5$ \\
\hline 3 & $77.8 \pm 2.4$ & $66.7 \pm 2.1$ & $59.3 \pm 1.4$ & $53.8 \pm 1.4$ & $85.4 \pm 1.2$ & $72.8 \pm 1.5$ & $64.4 \pm 1.8$ & $58.8 \pm 1.7$ & $99.9 \pm 1.1$ \\
\hline 4 & $86.2 \pm 1.2$ & $70.4 \pm 2.3$ & $64.9 \pm 1.7$ & $57.6 \pm 1.5$ & $94.7 \pm 1.7$ & $79.5 \pm 1.7$ & $71.3 \pm 1.9$ & $65.3 \pm 1.4$ & \\
\hline 5 & $96.5 \pm 1.6$ & $75.9 \pm 1.1$ & $70.5 \pm 1.8$ & $62.8 \pm 1.6$ & $99.5 \pm 1.7$ & $84.6 \pm 1.8$ & $76.5 \pm 1.2$ & $72.3 \pm 1.5$ & \\
\hline 6 & & $83.5 \pm 1.4$ & $74.4 \pm 1.7$ & $68.4 \pm 1.2$ & & $90.3 \pm 1.2$ & $82.7 \pm 1.5$ & $77.5 \pm 1.6$ & \\
\hline 7 & & $89.2 \pm 1.2$ & $78.3 \pm 1.9$ & $73.9 \pm 1.9$ & & $98.5 \pm 1.1$ & $87.5 \pm 1.7$ & $83.8 \pm 1.9$ & \\
\hline 8 & & $97.2 \pm 1.5$ & $83.9 \pm 1.7$ & $77.3 \pm 1.6$ & & & $93.7 \pm 1.6$ & $88.6 \pm 1.7$ & \\
\hline 9 & & $99.3 \pm 1.7$ & $89.5 \pm 2.3$ & $81.5 \pm 2.3$ & & & $99.8 \pm 1.2$ & $92.6 \pm 1.5$ & \\
\hline 10 & & & $95.1 \pm 1.2$ & $86.6 \pm 2.2$ & & & & $98.9 \pm 1.3$ & \\
\hline 11 & & & $99.5 \pm 1.3$ & $91.7 \pm 1.2$ & & & & & \\
\hline 12 & & & & $95.4 \pm 1.2$ & & & & & \\
\hline
\end{tabular}

\section{In vitro drug release}

The in vitro drug release study of ciprofloxacin from all formulations was carried out by USP type II dissolution apparatus containing 900 $\mathrm{ml}$ of $0.1 \mathrm{~N} \mathrm{HCl}$ at $37 \pm 0.9 \mathrm{C}$ at $50 \mathrm{rpm}$ for $12 \mathrm{~h}$, and the result was shown in fig. 6. Dissolution data is represented in table 3 . A significant decrease in the rate and extent of the drug release was observed with the increase in polymer concentration in in situ 
gelling preparation. The sodium alginate and HPMC with a primary role in the sol-gel phenomenon and buoyant also affected the release rate to some extent. F1, F2 and F3 released $96.5 \%, 99.3 \%$ and $99.5 \%$ in 5, 9 and $11 \mathrm{~h}$ of dissolution. Formulations F4 to $\mathrm{F} 6$ released $95.4 \%, 99.5 \%$ and $98.5 \%$ in 12,5 and $7 \mathrm{~h}$ of dissolution. Formulations F7, F8 released $99.8 \%, 99.9 \%$ in 9 and $10 \mathrm{~h}$ of dissolution respectively. Commercially available product (M), CIFRAN showed $99.9 \%$ drug release in $4 \mathrm{~h}$.

\section{Kinetics of drug release}

The cumulative amount of drug released from the systems at different time intervals was fitted to different kinetic models of zero order, first order, Higuchi model, Korsmeyer-Peppas model, and
Hixson-Crowell model to find out the mechanism of drug release. The in vitro release profile was fitted to various kinetic models in order to find out the mechanism of drug release. The goodness of fit was evaluated using the correlation coefficient $\left(\mathrm{r}^{2}\right)$ values. The correlation coefficient $\left(\mathrm{r}^{2}\right)$ for all the formulations using different kinetics equation is listed in table 4. The values of $r^{2}$ for all formulations were found higher for the first order model. It was found that all formulations mostly followed the first order models as the best fit model because of the higher value of $r$ (correlation coefficient). The release profile of in situ gelling formulations was treated with Korsmeyer-Peppas equation, and slope value $n \leq 0.45$ were indicating fickian diffusion [19]. Kinetic profiles of various formulations were shown in fig. 5,6,7 and 8.

Table 4: Different kinetic models applied on in situ gel formulations

\begin{tabular}{|c|c|c|c|c|c|c|c|}
\hline \multirow{2}{*}{ atch B } & \multicolumn{2}{|l|}{ Zero-order plot } & \multicolumn{2}{|c|}{ First order plot } & \multirow{2}{*}{$\begin{array}{l}\text { Higuchi plot } \\
\mathbf{r}^{2}\end{array}$} & \multirow{2}{*}{$\begin{array}{l}\text { Korsmeyer Peppas plot } \\
\text { n }\end{array}$} & \multirow{2}{*}{$\begin{array}{l}\text { Hixson crowell plot } \\
\mathbf{r}^{2}\end{array}$} \\
\hline & $\mathrm{K}_{0}\left(\mathrm{mg} . \mathrm{ml}^{-1} \mathrm{~h}^{-1}\right)$ & $\mathbf{r}^{2}$ & $K_{1}\left(h^{-1}\right)$ & $\mathbf{r}^{2}$ & & & \\
\hline F1 & 14.35 & 0.85 & 0.54 & 0.95 & 0.9539 & 0.23 & 0.9518 \\
\hline $\mathrm{F} 2$ & 7.99 & 0.88 & 0.42 & 0.91 & 0.9644 & 0.25 & 0.9602 \\
\hline F3 & 6.62 & 0.92 & 0.33 & 0.88 & 0.9747 & 0.25 & 0.9565 \\
\hline F4 & 5.53 & 0.91 & 0.16 & 0.98 & 0.9813 & 0.28 & 0.9813 \\
\hline F5 & 15.40 & 0.83 & 0.65 & 0.90 & 0.9608 & 0.25 & 0.9554 \\
\hline F6 & 8.67 & 0.87 & 0.38 & 0.93 & 0.9513 & 0.23 & 0.9396 \\
\hline F7 & 6.89 & 0.89 & 0.31 & 0.88 & 0.9685 & 0.32 & 0.9439 \\
\hline F8 & 6.16 & 0.93 & 0.26 & 0.94 & 0.9798 & 0.29 & 0.9766 \\
\hline M & 24.40 & 0.98 & 1.97 & 0.81 & 0.9920 & 0.69 & 0.9482 \\
\hline
\end{tabular}

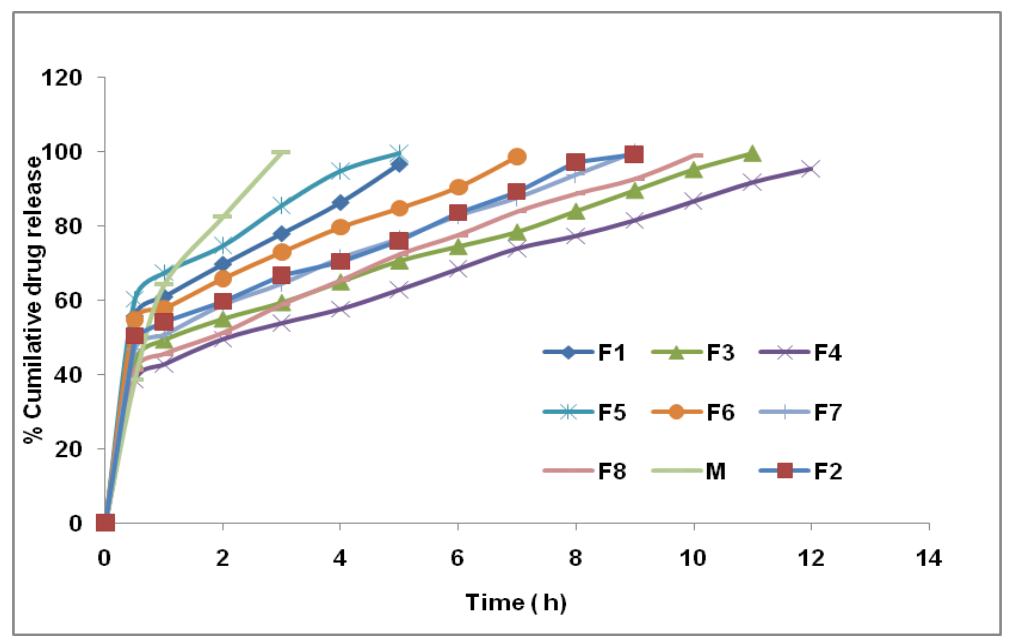

Fig. 5: Comparison of dissolution profiles of ciprofloxacin in situ gel formulations with CIFRAN

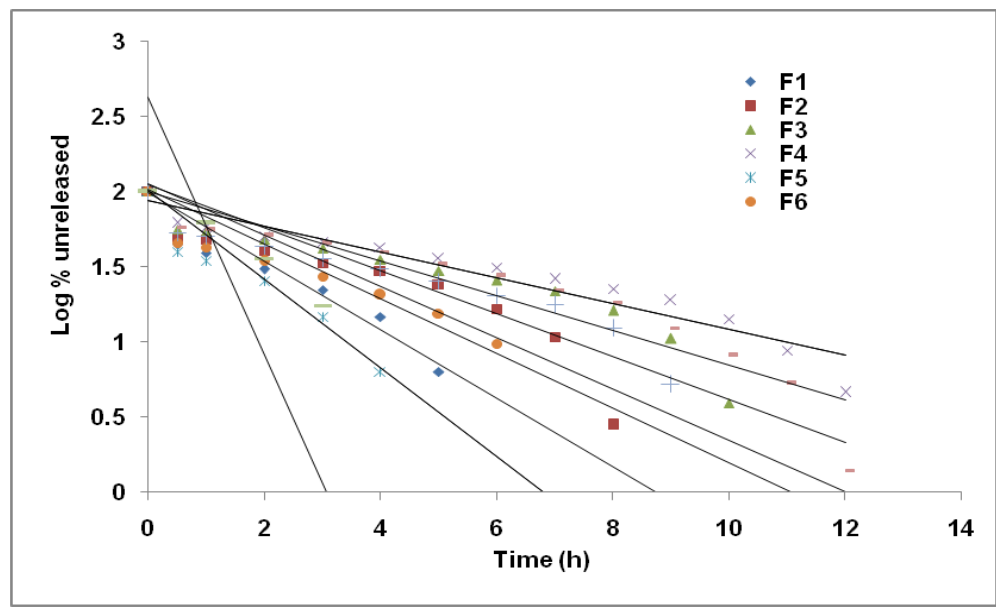

Fig. 6: First order plots of various formulations and marketed product 


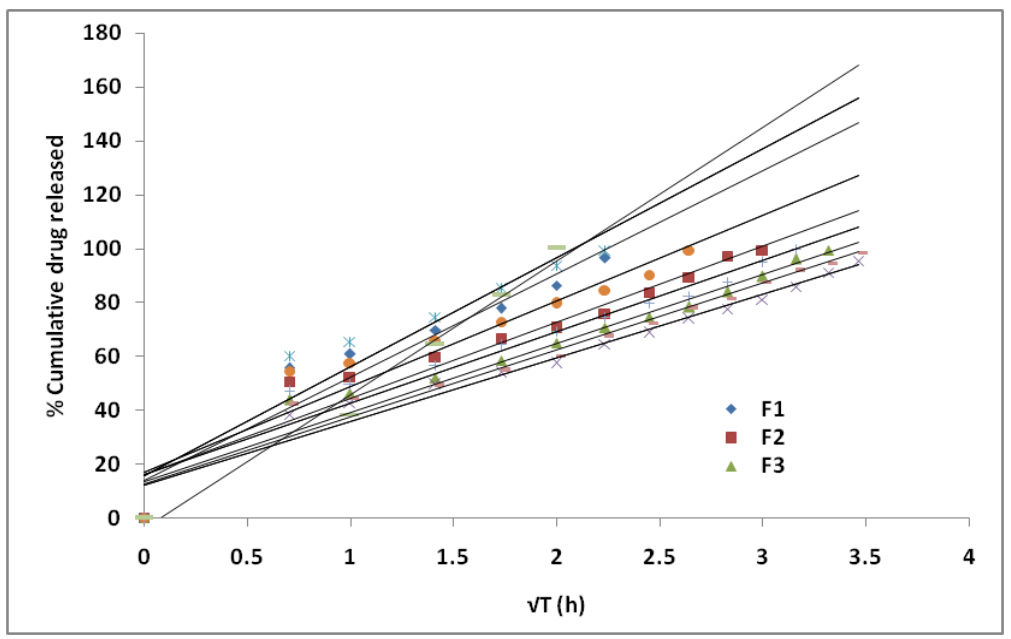

Fig. 7: Higuchi plots of various formulations and marketed product

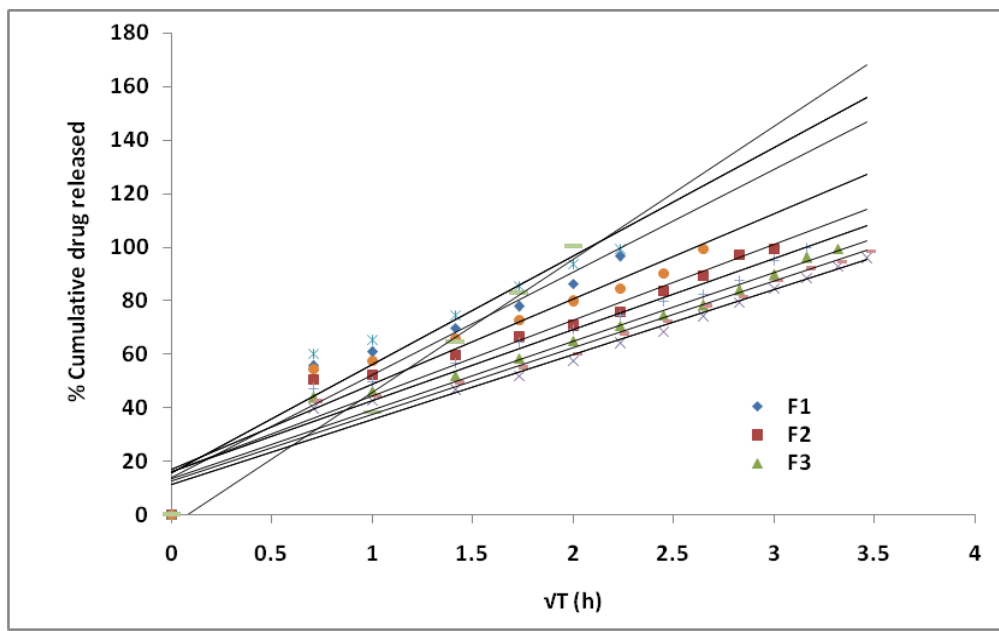

Fig. 8: Korsmeyer-peppas plot

\section{CONCLUSION}

The prepared formulations met al. 1 pre-requisites to become an in situ floating system, gelled and floated instantaneously in stomach $\mathrm{pH}$. The high concentration of calcium carbonate increased crosslinking of sodium alginate and form egg case like structures, more the cross-linking density less the penetration of water into the matrix and limited amount of drug that enters into dissolution fluid. Thereby the high concentration of sodium alginate along with HPMC K100M (increases strength of the gel) and calcium carbonate had sustained effect. Ciprofloxacin was successfully formulated at a $\mathrm{pH}$ triggered floating in situ gelling system using sodium alginate. The F4 formulation containing $4 \% \mathrm{w} / \mathrm{v}$ of sodium alginate, $0.4 \% \mathrm{w} / \mathrm{v}$ of HPMC $\mathrm{K} 100 \mathrm{M}$ and $4 \% \mathrm{w} / \mathrm{v}$ of calcium carbonate shows more sustained in vitro release $(95.7 \%)$ than other formulations over an extended period of $12 \mathrm{~h}$. The drug release from a gel structure follows a first-order type, and release pattern was fickian diffusion type.

\section{ACKNOWLEDGMENT}

I express my heartfelt gratitude to the A. U. College of Pharmaceutical Sciences, Andhra University for encouragement during the course of work.

\section{AUTHORS CONTRIBUTIONS}

All the author have contributed equally

\section{CONFLICT OF INTERESTS}

Declared none

\section{REFERENCES}

1. Chandra, Mohan SB, Manjunatha N, Patel K, Samanta MK, Bhaskaran S, et al. Design and development of oral sustained in situ gelling systems of famotidine. Indian J Novel Drug Delivery 2009;1:42-6.

2. Miyazaki S, Endo K, Kawasaki N, Kubo W, Watanabe H, Attwood $\mathrm{D}$, et al. Oral sustained delivery of paracetamol from in situ gelling xyloglucan formulations. Drug Dev Ind Pharm 2003;29:113-9.

3. Peppas N, Langer R. New challenges in biomaterials. Science 1994;263:15-20.

4. Rajinikanth S, Mishra B. Floating in situ gelling systems of acetohydroxamic acid for clearance of H. pylori. J Drug Dev Ind Pharm 2008;34:577-87.

5. Lena MT. Formulation and evaluation of floating oral in-situ gel of metronidazole. Int J Pharm Pharm Sci 2014;6:265-9.

6. Naik SB, Venkateswarlu K, Chandrasekhar KB. Formulation and in vitro evaluation of orodispersible tablets of olanzapine for the improvement of dissolution rate. J Chem Pharm Res 2016;8:177-81.

7. Varshosaz J, Tavakoli N, Roozbahani F. Formulation and in vitro characterization of ciprofloxacin floating and bioadhesive extended-release tablets. Drug Delivery 2006;13:277-85.

8. Rao S, Ratnam BV. Formulation and optimization of sustained release tablets of rosuvastatin using HPMC K4M, HPMC K100M, and carrageenan. Int J ChemTech Res 2018;11:376-86.

9. Nelson JM, Chiller TM, Powers JH, Angulo FJ. Fluoroquinoloneresistant campylobacter species and the withdrawal of 
fluoroquinolones from use in poultry. Clin Infect Dis 2007;44:977-80.

10. Drlica K, Zhao X. DNA gyrase, topoisomerase IV, and the 4quinolones. Microbiol Mol Biol Rev 1997;61:377-92.

11. Mulagada S, Baratam SR. Design and evaluation of ondansetron fast disintegrating tablets using natural polymers and modified starches as super disintegrants for the enhancement of dissolution. J Young Pharm 2017;9:519-24.

12. Maheswaran A, Padmavathy J, Nandhini V, Saravanan D, Angel P. Formulation and evaluation of floating oral in situ gel of diltiazem hydrochloride. Int J Appl Pharm 2017;9:50-3.

13. Patel MJ, Patel KR, Patel MR, Patel NM. Strategy for development of $\mathrm{pH}$-triggered floating in-situ gel of levetiracetam. Am J Pharm Tech Res 2012;2:828-41.

14. Vipul V, Basu B. Formulation and characterization of the novel floating in-situ gelling system for controlled delivery of ramipril. Int J Drug Delivery 2013;5:43-55.
15. Rao BS, Vijayaratna J, Ramarao CT. Optimization of matrix tablets containing alfuzosin $\mathrm{HCl}$ employing HPMC K4M. Eur J Pharm Med Res 2016;3:529-33.

16. Thomas LM. Formulation and evaluation of floating oral in-situ gel of metronidazole. Int J Pharm Pharm Sci 2014;6:265-9.

17. Patel DM, Patel CN. Formulation and evaluation of floating oral in-situ gelling system of amoxicillin. ISRN Pharm 2011;1:1-8.

18. Baratam SR, V RatnaJ. Formulation and evaluation of floating matrix tablets of levofloxacin hemihydrate using hydroxylpropyl methylcellulose $\mathrm{k} 4 \mathrm{~m}$ to treat Helicobacter pylori infection. Asian J Pharm Clin Res 2018;11:148-51.

19. Reddy RK, Srinivas M, Srinivas R. Once-daily sustained-release matrix tablets of nicorandil: formulation and in vitro evaluation. AAPS PharmSciTech 2003;4:480-8.

20. Hasan MJ, Kamal BA. Formulation and evaluation of ranitidine hydrochloride are floating In situ gel. Int J Pharm Pharm Sci 2014;6:401-5.

21. Nayak A, Maji R, Das B. Gastroretentive drug delivery system: a review. Asian J Pharm Clin Res 2010;3:1-10. 